SHORT REPORT

\title{
Images of body weight among young men and women: evidence from Beirut, Lebanon
}

\section{Khawaja, R A Afifi-Soweid}

I Arab society, plumpness was traditionally considered a trait of feminine perfection. Not now, and an increasing proportion of Lebanese adolescents considers thinness a marker of female beauty. Once a Western phenomenon, extreme thinness is now valued by young urban women almost everywhere, largely because of the propagation of thin models by the global media, satellite dishes, and fashion industries. Such a global trend has serious health consequences, including eating disorders and mental illness. Previous studies conducted in the UK have shown that women with a "normal" weight were more likely than men to consider themselves overweight. ${ }^{1}$ Furthermore, this gender gap in weight related concerns among adolescents increased with age. ${ }^{2}$ Do these conclusions hold true in a developing country's context?

The purpose of this paper is to investigate patterns of, and gender differences in, perception of body image as compared with actual body mass index among adolescents in a "transnational" college-the American University of Beirut—of a developing country. This study extends previous community based research on gender differences in self perception of body weight to include various measures of socioeconomic status of adolescents in a context very different from that of previous studies.

\section{METHODS}

We use data from the surveillance and intervention for behavioral risk factors survey (SIBER) of all entering students at the American University of Beirut (AUB), conducted in the autumn of 1998 by the AUB Faculty of Health Sciences. ${ }^{3}$ Established in 1866 by American missionaries, the AUB is one of the oldest liberal arts regional universities in the Arab world, with an international body of students and faculty. Although most (about 80\%) of the students at AUB are Lebanese, it has students from many countries in the region and beyond. A total of 954 eligible respondents aged 16-20 years completed the questionnaire over three consecutive days. The refusal rate was very low $(0.9 \%)$. A self administered questionnaire was designed to obtain data on a wide range of health risking and other lifestyle behaviour and sociodemographic characteristics of students and their parents. The survey instrument included a direct question on self image of body weight: "Are you trying to lose weight (1), gain weight (2), stay the same (3), or not trying to do anything (4)." In addition, the survey included two items on self reported weight in $\mathrm{kg}$ and height in metres to construct a conventional measure of BMI. Following previous studies, ${ }^{145}$ a cut off point of $25 \mathrm{~kg} / \mathrm{m}^{2}$ was used for adult overweight. Those adolescents with a BMI of less than $19 \mathrm{~kg} / \mathrm{m}^{2}$ were identified as "underweight". ${ }^{4}$

We used binomial logistic regression to investigate gender differences in the two binary outcomes, namely "actual" overweight and trying to lose weight. Our primary predictor was gender. Other control variables included age (16-17, 18, 19-20), overweight $\left(25 \mathrm{~kg} / \mathrm{m}^{2}\right)$ or body image (trying to lose

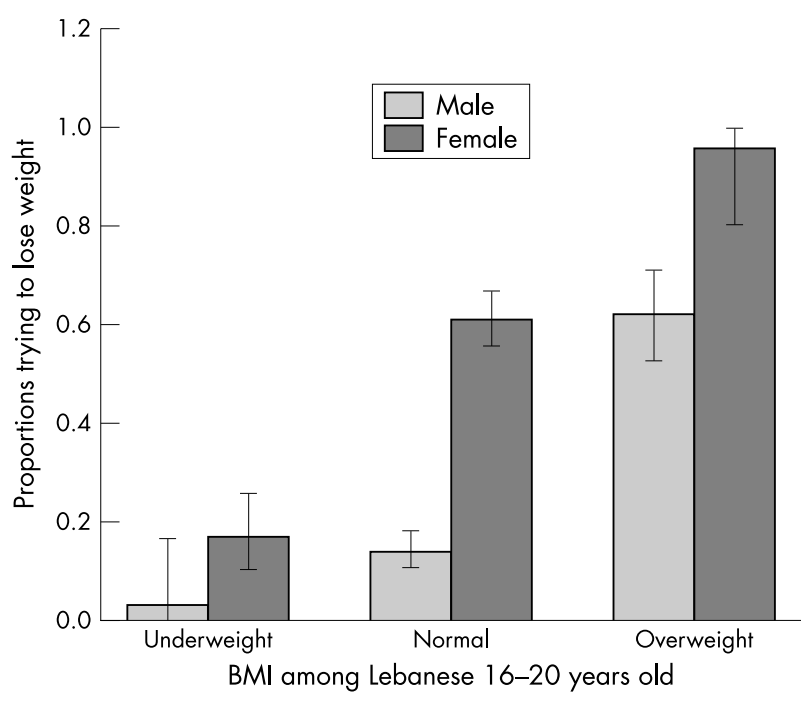

Figure 1 Trying to lose weight by actual BMI.

weight, other), ever lived outside Lebanon for at least one year (yes, no), and several indicators of SES: father's and mother's education (school/technical, university), mother's employment status (employed, unemployed/housewife), pocket money ( $\leqslant 50000 \mathrm{LL},>50000 \mathrm{LL})$.

\section{RESULTS}

Overall, $6.1 \%$ of female and $23.8 \%$ of male respondents were identified as overweight. However, significantly more women $(52.9 \%)$ than men $(24.5 \%)$ wanted to lose weight, and this held true across the actual body weight categories (fig 1). Among the overweight, most men (62\%, 95\%CI: 0.53 to 0.71$)$ and almost all women (96\%, 95\%CI: 0.80 to 0.99$)$ expressed a desire to lose weight. The gender gap was even more noticeable for those in the "normal" weight category, in which 61\% (95\%CI: 0.56 to 0.67 ) of women compared with only $16 \%$ (95\%CI: 0.11 to 0.18 ) of men, wanted to lose weight.

The findings (data not displayed) from logistic regression showed that men were surprisingly 4.9 times more likely to be overweight than women $(\mathrm{p}<0.0000)$, controlling for age, father's education, and mother's employment status, mother's education, pocket money, and ever lived outside Lebanon. Although previous findings from Western societies showed gender difference in overweight, the gender gap was either in favour of female ${ }^{2}$ for younger adolescents or smaller

Abbreviations: AUB, American University of Beirut; SIBER, surveillance and intervention for behavioral risk factors survey 
in magnitude. ${ }^{1}$ Other significant predictors of overweight were father's education and age of respondent. However, women were 10.8 times significantly more likely to perceive themselves as overweight than men $(\mathrm{p}<0.0000)$, controlling for their BMI, and the same other covariates. Age, actual BMI, and having lived outside Lebanon were significantly associated with trying to lose weight as would be expected. Among the socioeconomic status variables, only pocket money was positively associated with trying to lose weight, suggesting that the desire for thin bodies is slowly becoming a mass phenomenon.

\section{DISCUSSION}

Despite the fact that their BMIs were much less likely to be in the "overweight" range, women in this sample of 16-20 years olds were significantly more likely than men to consider themselves too heavy for their height and hence want to lose weight. Similar findings have been reported in previous studies in Western societies. The striking gender differences in "trying to lose weight," especially among those with normal weight, suggest that thinness is becoming more desired in Arab society, although reporting bias cannot be ruled out. This study relied on self reports of weights and height rather than actual measurements. We know from previous studies that women tend to underreport their weight as compared with men. Furthermore, the sample was based on a single "westernised" university, and cannot be generalised to other adolescents. However, the results do lend support to general perceptions of shifting desires for extreme thinness in the Arab region in response to the global media and advertisements on the walls by fashion companies. Further research is needed to understand the broader social context and magnitude of this phenomenon in the general population, and to develop appropriate health promotion strategies increasing awareness about appropriate (that is, normal) weight for height, especially for women.

\section{Authors' affiliations}

M Khawaja, Center for Research on Population and Health, Faculty of Health Sciences, American University of Beirut, Beirut, Lebanon

R A Afifi-Soweid, Department of Health Education and Behavior, Faculty of Health Sciences, American University of Beirut

Correspondence to: Dr M Khawaja, American University of Beirut, Faculty of Health Sciences, New York Office, 3 Dag Hammarskjold Plaza, 8th Floor, New York, NY 10017-2303, USA; mk36@aub.edu.lb

Accepted for publication 9 June 2003

\section{REFERENCES}

1 Emslie C, Hunt K, Macintyre S. Perception of body image among working men and women. J Epidemiol Community Health 2001;55:406-7.

2 Sweeting $\mathbf{H}$, West P. Gender differences in weight related concerns in early to late adolescents. J Epidemiol Community Health 2002:56:700-1.

3 Shediac-Rizkallah MC, Afifi-Soweid RA, Farhat T, et al. Adolescent healthrelated behaviors in postwar Lebanon: findings among students at the American University of Beirut. International Quarterly of Community Health Education 2000-2001;20:115-31.

4 Afifi-Soweid RA, Najem-Kteily MB, Shediac-Rizkallah MC. Preoccupation with weight and disordered eating behaviors of entering students at a university in Lebanon. Int J Eat Disord 2002;32:52-7.

5 Cole J, Bellizzi M, Flegal K, et al. Establishing a standard definition of child overweight and obesity worldwide: international survey. BMJ 2000;320: 1-6. 